\title{
HISTORICIDADE INSTITUCIONAL DO ENSINO DE ENFERMAGEM NA PARAÍBA: UMA CONTRIBUIÇÃO PARA O ESTUDO*
}

Daísy Vieira de A raújoํㅜ, Cesar Cavalcanti da Silva²

RESUM O: Trata-se de um artigo de atualização com o objetivo de relatar o percurso histórico do ensino de enfermagem na Paraíba, com enfoque nas transformações institucionais que determinaram alterações no curso de graduação em enfermagem do Centro de Ciências da Saúde da U niversidade F ederal da Paraíba - CCS/U FPB. Promove uma incursão sobre o ensino da enfermagem no B rasil, desde a criação de cursos para auxiliares de enfermagem, passando pelo ensino técnico, até o nível superior e relata os principais acontecimentos deste percurso na Paraíba. Deste modo, faz uma análise do estado da arte do processo de formação de recursos humanos de enfermagem em J oão Pessoa-PB, elucidando a legislação que o subsidia.

DESCRITORES: História; Enfermagem; Recursos humanos; Ensino.

\section{INSTITUTIONAL HISTORICITY OF NURSING TEACHING IN PARAÍBA STATE/ BRAZIL: A CONTRIBUTION FOR THE STUDY}

ABSTRACT: The present study is an excerpt of the dissertation for the author's master's degree and objectifies to track down the historical trail of nursing teaching in Paraíba State/B razil, focusing on institutional transformations that determined changes in the nursing graduation course of the Center of $\mathrm{H}$ ealth Sciences at the Federal U niversity of Paraíba - CCS/U FPB. It promotes an incursion on nursing teaching in Brazil, from the creation of courses for nursing assistants, technical courses up to the superior level, reporting the main historical events in Paraíba State. It is an updating article that intends to analyze the state- of- the- art process for nursing professional qualification in J oão Pessoa-Paraíba State, elucidating the underlying legislation.

DESCRIPTORS: History; Nursing; M anpower; Teaching.

\section{HISTORICIDAD INSTITUCIONAL DE LA ENSEÑANZA EN ENFERMERÍA EN PARAÍBA: UNA CONTRIBUCIÓN PARA EL ESTUDIO}

RESUMÉN: EI presente estudio es un recorte de la disertación de posgrado de la autora y tiene el objetivo de decir el curso histórico de la enseñanza en enfermería en Paraíba, con el enfoque en las transformaciones institucional es que determinaron las alteraciones en el curso de enfermería en el Centro de Ciencias de la Salud de la Universidad Federal da Paraíba - CCS/UFPB. Promueve una incursión en la enseñanza de enfermería en B rasil, de la creación de cursos para los auxiliares de enfermería, pasando por la enseñanza técnica, hasta el nivel superior, y dice los eventos principales de este curso en Paraíba. Es un artículo de actualización que pretende analizar el estado del arte del proceso para la formación de los recursos humanos en enfermería en J oão Pessoa - PB mientras elucida la legislación que lo subvenciona.

DESCIPTORES: Historia; Enfermería; Recurso humano, Enseñanza.

\footnotetext{
*A rtigo a partir da dissertação de mestrado: Formação de Força de Trabalho em Saúde: contribuição para a prática educativa em enfermagem. A no de defesa: 2006

${ }^{1}$ Enfermeira. Licenciada em Enfermagem. M estre em Enfermagem pelo Programa de Pós-Graduação em Enfermagem do Centro de Ciências da Saúde da Universidade Federal da Paraíba - CCS/UFPB. Professora da UNESC Faculdades.

${ }^{2}$ Enfermeiro. D outor em Enfermagem pela USP-SP. D ocente do Departamento de Enfermagem M édico-Cirúrgica e A dministração da UFB B.
}

R J oaquim Caroca, 220 - 58109-080 - Campina Grande-PB Recebido em: 20/03/07

E-mail: mestredaisy@yahoo.com.br 


\section{INTRODUÇÃO}

É fato que, no mundo globalizado, a rapidez e a agilidade na busca e resgate de informações fazem muita diferença em qualquer área do conhecimento. Em uma profissão jovem como é o caso da enfermagem profissional, saber de onde viemos, em que patamar esta se encontra e onde desejamos chegar, são condições fundamentais para o levantamento de diferentes bandeiras de lutas no âmbito do processo de trabal ho da saúde.

N o B rasil, a constituição de recursos humanos em saúde tem sido reconhecida como um elemento crítico no processo de reorientação e transformação dos sistemas de saúde, mas pouco se tem produzido sobre a história das instituições formadoras. Essa área, cuja complexidade de problemas requer uma aproximação interdisciplinar, não tem sido tratada com a relevância política, que merece.

As questões relacionadas à constituição de recursos humanos para a saúde e instituições formadoras jamais deixaram de ser motivo de preocupação para trabalhadores, gestores e formadores. A o longo dos últimos anos, poucas, porém, importantes análises encetaram diferentes propostas que, se houvesse sido implantadas, quer pelos gestores, ou pelos formadores, teriam minorado grande parte das distorções que hoje af etam o trabal ho na saúde.

Revendo a literatura sobre as investigações a respeito da historicidade e dinamicidade do ensino superior de enfermagem no Brasil, verifica-se que, entre as décadas de 50 e 60 do século passado, foi muito comum a ocorrência de estudos de inspiração predominantemente pedagógicos, voltados para os processos de formação de trabalhadores de saúde de nível universitário, e de estudos descritivos sobre a oferta de pessoal de saúde e sua distribuição geográfica. Nas décadas de 70 e 80, as investigações agrupadas sob a denominação de organização social das práticas de saúde não apresentaram resultados imediatamente aplicáveis, entretanto, subsidiaram estudos concretos, consolidados sob a denominação de força de trabalho em saúde que em muito contribuíram para a compreensão do conjunto de trabalhadores de saúde como um todo articulado e não mais um somatória de técnicos ${ }^{(1)}$.

A pesar de toda a produção acadêmica, e dos inúmeros eventos relacionados ao tema formação de recursos humanos na área da saúde, este, quase sempre foi tratado de forma dissociada da problemática das instituições de ensino que figuram com mais predominância nas pesquisas de natureza educacional. N esse sentido, o conhecimento da evolução do ensino da enfermagem visualizada sob o ponto de vista das instituições e, particularmente, sobre sua processual idade histórica, constitui relevante esforço rumo à superação de contradições visualizadas neste campo e um importante aliado no mundo gl obalizado do terceiro milênio.

A ssim, este artigo tem o objetivo de relatar 0 percurso histórico do ensino de enfermagem na Paraíba, com enfoque nas transformações institucionais que determinaram alterações no curso de graduação em enfermagem do Centro de Ciências da Saúde da U niversidade Federal da Paraíba - CCS/ UFPB

\section{NASCIMENTO DO ENSINO SUPERIOR DE ENFERMAGEM NO BRASIL}

Oficial mente a primei ra escola de enfermagem do Brasil foi a Escola de Enfermagem do Departamento N acional de Saúde Pública - EED NSP, criada pelo Decreto 15.799 de 10/11/1922, anexo ao Hospital G eral deA ssistência do DNSP e que passou a funcionar em 19/03/1923. Entretanto a Escola Profissional de Enfermeiros e Enfermeiras, posteriormente chamada EscolaA Ifredo Pinto, criada através do decreto 791 do governo Provisório da República, data de 1890. Essa escola foi criada nos moldes da escola Sal petriere na França, para atender a uma necessidade de pessoal do Hospício Nacional de Alienados ou H ospício Dom Pedro II (2).

A criação da EEDNSP teve apoio da Fundação Rockefeller que por sua vez tinha objetivos bem definidos em relação à A mérica L atina, ou seja, criar condições sanitárias adequadas ao desenvolvimento capitalista e garantir a certeza do ressarcimento dos empréstimos iniciados no governo de E pitácio Pessoa. Segundo Paula e B raga ${ }^{(3)}$ sua atuação estava explícita e coincidentemente vinculada aos interesses econômicos do grupo Rockefeller, nos países subdesenvolvidos. Em 1926, portanto, três anos depois da data que marcou o início de seu funcionamento, a EEDNSP passou a chamar-se Escola de Enfermeiras Dona A na Néri. Inicialmente esta escola foi considerada complementar da Universidade do B rasil e, somente depois do Decreto 21.321 de 18/06/1946 é que passou a pertencer a Universidade do $\mathrm{B}$ rasil ${ }^{(2)}$. 
O Programa deEnsino da Escola deEnfermagem do DNSP era semelhante ao currículo das escolas de enfermagem americanas, standard curriculum for nursins schools. Constava de curso com duração de 3 anos; secundário como pré-requisito para admissão; ênfase no ensino teórico e 48 horas semanais de prática. No mesmo ano do início de funcionamento da EEDNSP, foi publicado o relatório GOLDMARK, que apontava falha neste currículo e recomendava o ingresso de algumas escolas, na universidade. $\mathrm{N}$ o B rasil o curso tinha as seguintes características: duração de 2 anos e 4 meses - 28 meses; duas semanas de férias anuais; exigência de diploma de escola normal ou aprovação em exame de seleção, período probatório de 4 meses; 48 horas semanais de prática; direito a residência (a primeira foi uma casa vizinha ao hospital São Francisco de Assis); direito a uma pequena remuneração mensal ${ }^{(2)}$.

A primeira reformulação do currículo de enfermagem se deu pelo Decreto 27.426, quando da promulgação da Lei 775 de 06 de A gosto de 1949, que passou a regular o ensino da Enfermagem em todo o país. A lei 775/49 determinava que as escolas pudessem receber candidatos com certificado do curso ginasial por um período de sete anos, expirado este prazo, a L ei 2.995/56 o prorrogou por mais cinco anos, quando então, todas as escolas passaram a exigir 0 curso secundário ou equivalente como pré-requisito para admissão ao curso de enfermagem.

A Lei 775/49 também oficializou a formação de auxiliares de enfermagem. A idéia de se criar um curso para formação de auxiliares de enfermagem, nasceu em 1934, com Dona Laís N etto dos Reis, em Belo Horizonte, sendo o primeiro curso ministrado em 1941 na Escola de Enfermagem A na Néri, oficializado em 1949. No tocante aos conteúdos, a mudança provocada pelo advento da Lei 775/49, que reformulou o ensino de enfermagem, pouca coisa foi modificada em relação ao primeiro programa de ensino, pois ambos privilegiavam as disciplinas de caráter preventivo, embora o mercado já apontasse em uma forte tendência para a área hospitalar.

Das décadas de 1930 a 1960 do século passado, o sistema agrário exportador brasileiro cedeu lugar a implantação da industrialização com base em um processo de substituição de importações. Esse período ficou conhecido como o de maturação da burguesia brasileira. Para consolidar seu domínio e garantir a acumulação de capital, a burguesia nascente se viu obrigada a formar um pacto, com a classe média e com os trabalhadores, essa situação possibilitou uma grande articulação da classe trabalhadora, principalmente no período em que J oão Goulart foi presidente (1961-1964) fazendo com que a burguesia passasse a temer pela perda de sua hegemonia. 0 pacto foi rompido em 1964 e entrou em cena o capital monopolista internacional que junto com o Estado Militar autoritário, passou a controlar a direção do processo econômico e político nacional ${ }^{(3)}$.

Visando proteger o processo acumulativo, 0 país adotou a partir de 1964, um rigoroso sistema de repressão política e aperfeiçoou o modelo econômico concentrador de renda. Fruto das medidas tomadas pelo Estado autoritário pós 64 , ocorreu um novo ciclo de expansão econômica, conhecido como "M ilagre B rasileiro" entre os anos de 1968 e 1973 do século passado, que ocorreu graças a uma severa repressão da classe trabalhadora e mecanismo de proteção do capital.

Foi nesse contexto político, econômico e social que surgiu um novo currículo de enfermagem em 1962, sob a égide do Parecer 271/62 do Conselho Federal de Educação. Segundo A nayde Correia de Carvalho(4), até 0 início dos anos 60 a enfermagem era considerada uma profissão com características próprias que justificavam uma legislação à parte. Influenciada pelos acontecimentos que movimentavam toda a sociedade, os setores intelectuais da profissão passaram a lutar por sua integração total ao sistema geral de ensino do país. A luta desses intelectuais da enfermagem cul minou com a colocação de duas emendas na Lei 4.024, de 20 de dezembro de 1961, que instituiu a Lei das Diretrizes e Bases da Educação Nacional. U ma no parágrafo único do artigo 47, que possibilitou o surgimento do ensino técnico de grau médio para o pessoal de enfermagem e nos artigos 90 e 91 que passava a incluir a assistência de enfermagem ao escolar, uma vez que antes, este direito cabia apenas ao médico e ao dentista. $\mathrm{Na}$ prática isto possibilitou o surgimento dos cursos técnicos em enfermagem através do Parecer 171/66 e da colocação da enfermagem como curso superior.

Com a Reforma Universitária, instituída pela Lei 5.540, de 28 de novembro de 1968, ocorreu uma nova mudança no currículo de enfermagem movida pelo Parecer 163/72 que incentivava o enfermeiro a dominar cada vez mais as técnicas avançadas da saúde, em razão da evolução científica, sem, no entanto, nada contribuir para a solução dos problemas básicos de saúde. A novidade deste Parecer foi a introdução das disciplinas Sociologia e Psicologia no currículo de 
enfermagem, além das habilitações em Saúde Pública, M édico-Cirúrgica e Obstetrícia que eram cursadas no último semestree atendiam aos interesses do capitalismo, visualizado na saúde pelo incentivo ao consumo desmedido de medicamentos efavorecimento à indústria de equipamentos médico-hospitalares, daí também, 0 grande incentivo ao domínio da técnica.

Em 1991 foi encaminhada uma proposta de reformulação do currículo mínimo fundamentada em discussões sobre o perfil sanitário e epidemiológico da população, organização dos serviços de saúde, processo de trabal ho em enfermagem e articulação entre ensino e serviço. Entrava em cena um novo modelo assistencial. Essa proposta resul tou no Parecer 314, de 06 de abril de 1994, que reformulou o currículo mínimo de enfermagem. As habilitações foram extintas, a carga horária mínima passou a ser de 3.500 horas/aula, incluindo 500 horas destinadas a estágio curricular com duração não inferior a dois semestres letivos, desenvolvidos sob supervisão docente.

Em 23 de dezembro de 1996, foi publicado no Diário Oficial da U nião a nova L ei das Diretrizes e B ases da Educação Nacional-LDB (L ei 9.394/96) que reiterou algumas posições da LDB de 1961 e atribui a responsabilidade da educação à família e ao Estado. $A$ nova L DB também trouxe novas responsabilidades para as instituições de Ensino Superior, docentes, discentes e sociedade, pois permitiu a formação de diferentes perfis profissionais a partir da vocação de cada curso e escola, esperando melhor adaptação ao mundo do trabalho já que as instituições teriam liberdade para definir parte considerável de seus currículos plenos.

\section{NASCIMENTO DO ENSINO SUPERIOR DE ENFERMAGEM NA PARAÍBA}

0 ensino de Enfermagem na Paraíba remonta a 1933 quando o Decreto M unicipal $n^{\circ} .272$, de 30 de junho, instituiu um curso para o treinamento teóricoprático de enfermeiros, na então, Diretoria deA ssistência Pública(5).

A criação da Escola deA uxiliares deE nfermagem da Paraíba antecedeu a criação do curso superior e ocorreu em 24 de janeiro de 1953, por meio do DecretoLei $n^{\circ}$. 343. Em 10 de julho de 1954 foi criada a Escola de Enfermagem da Paraíba, pelo Decreto-Estadual $n^{\circ}$. 1064, sob a tutela do Departamento Estadual de Saúde. Quatro anos depois, seu funcionamento foi autorizado pela Portaria M inisterial $n^{\circ}$. 365, de 9 de junho de 1958. Essa escola tinha como meta preparar enfermeiros de alto padrão e auxiliares de enfermagem ${ }^{(6)}$.

Com a criação da U niversi dade da Paraíba em 2 de dezembro de 1955, sob a égide da Lei $n^{\circ}$. 1366, a Escola de Enfermagem passou a integrá-la, como escola autônoma. A pós a federalização desta instituição por força da Lei $n^{\circ}$. 3835, de 13 de dezembro de 1960, a Escola de Enfermagem passou a ser um departamento anexo à Faculdade de M edicina(7).

No início da década de 60, com o advento dos currículos mínimos para o ensino das carreiras universitárias no Brasil, o currículo de Enfermagem previa a formação de enfermeiros em três anos letivos com possibilidade de acréscimo de mais um ano, destinado à habilitação em saúde pública ou obstetrícia. A lém disso, o documento uniformizou as exigências de escolaridade e de concurso de habilitação para o ingresso ao curso, que passou a ser de nível superior.

Em 1968 a L ei da R eforma U niversitária instituiu o ciclo geral de estudos para recuperar fal has evidenciadas pelo vestibular e proporcionar estudos básicos para os ciclos seguintes. Criaram-se as licenciaturas curtas nas áreas detecnologia ede educação; conferiu-se aos currícul os dos cursos de graduação certa flexibilidade permitindo-se às Instituições de Ensino Superior - IES que os complementasse, desde que obedecidos os mínimos de conteúdos estabelecidos pelo Conselho Federal de Educação - CFE ${ }^{(8)}$.

Segundo Perez ${ }^{(9)}$, realizou-se em 1973, no âmbito da U niversidade Federal da Paraíba, por efeito da L ei da R eforma U niversitária, a reforma cêntrica, com base na Resolução $n^{\circ} .12 / 73$ do Consel ho Superior U niversitário - CONSU NI, determinando a criação de seis Centros, os quais agrupavam Departamentos e Coordenações de cursos afins. 0 Centro de Ciências da Saúde - CCS foi um dos seis centros criados e a ele foi incorporada a Escola de Enfermagem, sendo criada a Coordenação do Curso de Graduação em Enfermagem.

Em 1989, o Departamento de Enfermagem foi desmembrado em duas unidades administrativas Departamento de Enfermagem de Saúde Pública e Psiquiatria -DESPP e Departamento de Enfermagem M édico - Cirúrgica e A dministração - DEM CA, responsáveis pelo oferecimento da maior parte das disciplinas do curso de graduação em enfermagem.

No que diz respeito à formatação curricular, no início de 1972, foi aprovado o Parecer $n^{\circ}$. 163/72 e a Resolução $n^{\circ}$. 4/72, fixando o currículo mínimo dos cursos de Enfermagem e 0 bstetrícia. 0 currículo passou a compreender três partes sucessivas: a) a pré- 
profissional, incluindo matérias do primeiro ciclo, as chamadas disciplinas do básico (anatomia, histologia, fisiologia, embriologia, dentre outras) comuns a todos os cursos da área de ciências da saúde; b) tronco profissional comum, levando à graduação do enfermeiro e habilitando-0 ao acesso a parte seguinte; c) habilitações (opcional), conduzindo à formação do enfermeiro médico-cirúrgico, obstetra ou de saúde pública. Incluindo, ainda, a licenciatura em enfermagem como uma quarta opção.

0 Parecer $n^{\circ}$. 163/72 e a Resolução n. 4/72 do CFE orientaram as Resoluções de $n^{\circ}$. 03/74 e 11/74 do Conselho de Ensino, Pesquisa e Extensão - CONSEPE da UFPB. A primeira estabelecia para o curso de enfermagem a estrutura curricular do primeiro ciclo de estudo, também denominada de tronco comum, cujas disciplinas eram ministradas em blocos, constituindo-se em unidades curriculares integradas. A segunda al terava a resolução anterior, estabelecendo o currículo pleno de enfermagem. Incluía uma habilitação geral e, a partir desta, habilitações específicas, a saber: enfermagem médico-cirúrgica, saúde pública, e obstetrícia(6).

A partir de então, o curso de graduação em enfermagem passou a ter uma carga horária mínima de 2.500 horas para habilitação geral, podendo chegar a 3.060, compreendendo as habilitações específicas. Das habilitações específicas, a de saúde pública tinha a menor carga horária ${ }^{(6)}$. A s normas para funcionamento dessas habilitações foram estabelecidas através da Resolução $n^{\circ}$. 19/77 do CONSEPE, cuja operacionalização assumiu a forma deinternato, com uma carga horária de 600 horas, desenvolvidas após a habilitação geral.

A Resolução n. 08/76 do CON SEPE ea Portaria $n^{\circ}$. 01/76 da Pró-R eitoria de Graduação fixaram as normas para a adaptação da estrutura das unidades curriculares aos alunos que ingressavam na UFPB no primeiro período letivo de 1976 e anteriores. Começava a divisão e alocação de conteúdos por cursos. Para 0 curso de enfermagem essa Resolução previa alterações na unidade curricular III, especificamente para os cursos de Nutrição e Enfermagem, integrando disciplinas comuns aos dois cursos e vigorou, a partir do segundo período de 1976, no curso de enfermagem ${ }^{(6)}$.

A Resolução $n^{\circ}$. 04/77 do CONSEPE estabeleceu uma nova estrutura curricular al terando a R esolução $\mathrm{n}^{\circ}$. 11/74, estabelecendo o currículo pleno de Enfermagem que passou a contar com uma parte comum - habilitação geral com carga horária de 2.835 horas e uma parte diversificada conduzida a partir da habilitação geral - as habilitações específicas em enfermagem médico- cirúrgica, obstétrica e de saúde pública com carga horária de 600 horas. No total, o curso passou a dispor de uma carga horária de 3.435 horas e a licenciatura em enfermagem de 435 horas $^{(6)}$.

Em 1980, a Resolução de $n^{\circ}$. 54/80 estabeleceu outra estrutura curricular. As principais alterações estruturais dessa proposta de reformulação curricular envolveram: a) a extinção das habilitações, assegurandose a integralidade e a terminalidade da formação do enfermeiro sem incluir fal sas e precoces especial izações; b) o aumento da duração mínima do curso em horas e anos (duração mínima de 3.500 horas, integralizadas no mínimo de 4 e no máximo de 5 anos, incluindo-se 0 estágio curricular supervisionado em nenhuma hipótese inferior a 2 semestres letivos; c) o redimensionamento, dos conteúdos das áreas de ciências humanas e biológicas; d) conteúdo mínimo abrangendo cinco áreas temáticas: bases biológicas e sociais da enfermagem; fundamentos da enfermagem; assistência de enfermagem; administração de enfermagem; e ensino de enfermagem.

A proposta instituiu para os enfermeiros a competência para desenvolverem atividades em quatro áreas fundamentais - assistencial, administrativa, ensino e produção científica, reforçando a formação do enfermeiro para o processo de trabal ho em enfermagem a partir de uma educação transformadora, que incitasse à reflexão e a indagação sobre a prática profissional e a valorização do compromisso do enfermeiro para com a sociedade.

A tendendo a este chamado nacional, o Curso de Enfermagem da UFPB, por intermédio da R esolução de $n^{\circ}$. 03/96, do CONSEPE, passou a contar com duas habilitações: a graduação, com duração mínima de 4.050 horas/aula e mais o estágio supervisionado ao final do curso; ea L icenciatura em Enfermagem, cursada após a conclusão do bacharelado(6).

No decorrer da implementação dessa nova estrutura curricular, constatou-se a ocorrência de grande número de disciplinas em um mesmo período; tempo reduzido para que os alunos realizassem atividades extracurriculares; desarticulação entre disciplinas e dissociação entre teoria e prática, o que suscitou a necessidade de readequação curricular e implementação do projeto político-pedagógico para o curso $^{(6)}$.

Depois da Constituição de 1988, quando a saúde foi reconhecida como um direito de cidadania e se instituiu o SUS como política de saúde, requerendo um novo perfil profissional, os vários cursos da área da saúde passaram a discutir a necessidade de revisão do ensino. 
$\mathrm{Na}$ área de Enfermagem, na UFPB, desde 1995 os departamentos passaram a repensar a formação dos alunos, vislumbrando profissionais comprometidos com a sociedade e com os problemas de saúde, numa perspectiva de articulação teoria e prática, dentro deuma visão crítica da real idade e considerando a complexidade do ser humano e o contexto em que ele vive.

Nesse sentido, em maio de 2002, o Núcleo de Estudos em Saúde Coletiva - NESC, o CCS/UFPB e a Pró-Reitoria de Graduação da UFPB promoveram uma oficina de trabal ho intitulada: Construindo movimentos integrados de mudanças curriculares integrais nos cursos daárea desaúde. Constituiu-seum momento de discussão nas IES e em especial na Universidade Federal da Paraíba, objetivando construir identidades no âmbito do Centro de Ciências da Saúde para desenvolver estratégias integrais e integradoras de mudança nos currículos de seus cursos ${ }^{(10)}$.

A s discussões explicitaram a necessidade de um amplo movimento construído a partir da cooperação, envolvimento e compartilhamento de experiências, o que torna necessário a cada segmento da universidade, do aparelho produtor deserviços de saúde e da comunidade, a potencialização de possibilidades de ação em torno de movimentos efetivos enegociados, construídos deforma ativa, participativa e integradora dos interesses de cada segmento ${ }^{(10)}$.

A tual mente, um grupo de professores designados pelos departamentos de Enfermagem do Centro de Ciências da Saúde da U niversidade Federal da Paraíba vem se reunindo semanalmente, com o objetivo de construir um Projeto Político-Pedagógico que oriente 0 processo de formação de profissionais de enfermagem em consonância com os requerimentos legais e perfis capazes de responder às exigências locais.

\section{CONSIDERAÇÕES FINAIS}

0 ensino de enfermagem na Paraíba, especificamente no curso de graduação do CCS/UFPB, teve um modelo de formação que privilegiava as ciências biológicas, segundo os moldes norte-americanos, que nortearam a formação inicial dos enfermeiros no B rasil, voltado para a assistência curativa e individual, desenvolvido mediante o emprego de procedimentos técnicos e com valorização da especialização precoce. Contudo, o curso apresentou uma série de avanços na sua estrutura curricular, a exemplo do aumento da carga horária, valorização das disciplinas das ciências humanas, formação generalista, sem a necessidade das especializações prematuras. A mparado pela Resolução $n^{\circ} .03 / 01$ queinstitui as Diretrizes Curriculares $N$ acionais para o Curso de Graduação em Enfermagem, o curso de enfermagem do CCS/UFPB tem buscado formar indivíduos críticos, criativos, autônomos e reflexivos para atender as necessidades sociais da saúde, com ênfase no Sistema Ú nico de Saúde - SUS.

\section{REFERÊNCIAS}

1. Ministério da Saúde (BR). Secretaria Executiva. Coordenação Geral de Desenvolvimento de Recursos Humanos para o SUS. A investigação sobre recursos humanos em saúde. B rasília (DF): M inistério da Saúde; 1993.

2. Barreira IA . Os primórdios da Enfermagem M oderna no Brasil. Rev Enferm da Escol A nna Nery 1997; no especial de lançamento.

3. Paula SG, B raga JCS. Saúde e previdência: estudos de política social. São Paulo: Hucitec; 1986.

4. Carval ho AC. A ssociação B rasileira de Enfermagem 1926 - 1976. D ocumentário. São Paulo; 1976.

5. Nóbrega H. As Raízes das Ciências da Saúde na Paraíba: medicina, odontologia e enfermagem. João Pessoa: UFPB; 1979.

6. Paraíba. Projeto Político Pedagógico do Curso Graduação em Enfermagem. João Pessoa: UFPB; 2002a.

7. Limeira M D. FormigaZS UFPB : implicações políticas e sociais de sua história. J oão Pessoa (PB) 1986; (11). Disponível em: http://www.ufpb.br/inst

8. A Imeida M CS. Tendências Pedagógicas na Formação do Enfermeiro em J oão Pessoa-PB [dissertação]. J oão Pessoa (PB): Universidade Federal da Paraíba; 1992.

9. Perez VL et al. Retrospectiva histórica do curso de habilitação de auxiliar de enfermagem. R ev CCS 1995; edição comemorativa dos vinte anos: 17-18.

10. Paraíba. Relatório Final. Oficina de Trabalho: Construindo M ovimentos Integrados de Mudanças Curriculares Integrais nos Cursos da Á rea de Saúde. J oão Pessoa (PB): UFPB; 2002b. 